\title{
Application of Transition-Metal Catalysis, Biocatalysis and Flow Chemistry as State-of-the-Art Technologies in the Synthesis of LCZ696
}

Xingxian Gu, ${ }_{1}^{1}$ Jibin Zhao, ${ }^{1}$ Like Chen, ${ }^{1}$ Yunzhong Li,${ }^{1}$ Bo Yu, ${ }^{1}$ Xiangguang Tian, ${ }^{1}$ Zhongcheng Min, ${ }^{1} \mathrm{Su} \mathrm{Xu},{ }^{1}$ Huijuan Gu, ${ }^{1}$ Junjie Sun, ${ }^{1}$ Xiaoquan Lu, ${ }^{1}$ Meng Chang, ${ }^{1}$ Xufan Wang, ${ }^{1}$ Liqun Zhao, ${ }^{1}$ Shengqing Ye, ${ }^{1}$ Hongwei Yang, ${ }^{1}$ Yingtao Tian, ${ }^{1}$ Feng Gao, ${ }^{1}$ Yu Gai, ${ }^{1}$ Guanghua Jia, ${ }^{2}$ Jingjing Wu, ${ }^{2}$ Yan Wang, ${ }^{2}$ Jianghua Zhang, ${ }^{2}$ Xuesong Zhang, ${ }^{2}$ Weichun Liu, ${ }^{2}$ Xin Gu, ${ }^{2} \mathrm{Xi}$ Luo, ${ }^{2}$ Hai Dong, ${ }^{2}$ Huaimin Wang, ${ }^{2}$ Berthold Schenkel, ${ }^{3}$ Francesco Venturoni, ${ }^{3}$ Paolo Filipponi, ${ }^{3}$ Bertrand Guelat, ${ }^{3}$ Thomas Allmendinger, ${ }^{3}$ Bernhard Wietfeld, ${ }^{3}$ Pascale Hoehn, ${ }^{3}$ Nikola Kovacic, ${ }^{3}$ Luca Hermann, ${ }^{3}$ Thierry Schlama, ${ }^{3}$ Thomas Ruch, ${ }^{3}$ Nadine Derrien, ${ }^{4}$ Philippe Piechon, ${ }^{5}$ and Florian Kleinbeck ${ }^{3, *}$

\footnotetext{
${ }^{1}$ Suzhou Novartis Technical Development Co., Ltd., \#18-1 Tonglian Road, Bixi Subdistrict, Changshu City, Jiangsu Province, 215537, P. R. China

${ }^{2}$ Novartis Pharmaceuticals (China) Suzhou Operations, \#18 Tonglian Road, Riverside Industrial Park Changshu Economic Development Zone, Changshu, Jiangsu Province, 215537, P. R. China

${ }^{3}$ Chemical \& Analytical Development, Novartis Pharma AG, 4056 Basel, Switzerland

${ }^{4}$ Pharmaceutical \& Analytical Development, Novartis Pharma AG, 4056 Basel, Switzerland

${ }^{5}$ Novartis Institutes for Biomedical Research, Novartis Pharma AG, 4056 Basel, Switzerland

*Corresponding author; e-mail: florian.kleinbeck@novartis.com
}

\section{Supporting Information}




\section{Table of content}

1. Crystallographic data $\quad$ S3

2. NMR spectra $\quad$ S6

3. HPLC data $\quad$ S14

4. RC1 data $\quad$ S15

$\begin{array}{ll}\text { 5. Equipment for flow reaction } & \text { S17 }\end{array}$ 


\section{Crystallographic data}

Crystal data and structure refinement for dianion $\mathbf{1 4}$ are summarized in Table S1.

Table S1: Crystal data and structure refinement for dianion 14

\begin{tabular}{ll}
\hline Parameter & Result \\
\hline Empirical formula & $\mathrm{C} 64 \mathrm{H} 92 \mathrm{Cl} 4 \mathrm{Mg} 4 \mathrm{O} 13$ \\
\hline Formula weight & 1308.42 \\
\hline Temperature & $100(2) \mathrm{K}$ \\
\hline Wavelength & $1.54178 \AA$ \\
\hline Crystal system & Monclinic \\
\hline Space group & $\mathrm{P} 21 / \mathrm{n}$ \\
\hline Unit cell dimensions & $\mathrm{a}=19.113(5) \AA, \alpha=90^{\circ}$ \\
& $\mathrm{b}=17.823(5) \AA, \beta=100.954(15)^{\circ}$ \\
& $\mathrm{c}=19.861(6) \AA, \gamma=90^{\circ}$ \\
\hline Volume & $6642(3) \AA^{3}$ \\
\hline Z & 4 \\
\hline Density (calculated) & $1.308 \mathrm{~g} / \mathrm{cm}^{3}$ \\
\hline Absorption coefficient & $2.479 \mathrm{~mm}{ }^{-1}$ \\
\hline F(000) & 2784 \\
\hline Crystal size & $0.06 \times 0.05 \times 0.02 \mathrm{~mm}^{3}$ \\
\hline Theta range for data collection & 2.94 to $68.29^{\circ}$ \\
\hline Index ranges & $-23 \leq \mathrm{h} \leq 22,-21 \leq \mathrm{k} \leq 21,-23 \leq 1 \leq 23$ \\
\hline Reflections collected & 72046 \\
\hline Independent reflections & $12123[\mathrm{R}($ int $)=0.1075]$ \\
\hline Completeness to theta $=68.29^{\circ}$ & $99.6 \%$ \\
\hline Absorption correction & Semi-empirical from equivalents \\
\hline Maximum and minimum & 0.9521 and 0.8655 \\
transmission & \\
\hline Refinement method & Full-matrix least-squares on F2 \\
\hline Data/restraints/parameters & $12123 / 1455 / 929$ \\
\hline Goodness-of-fit on $\mathrm{F}^{2}$ & 1.009 \\
\hline Final R indices $[\mathrm{I}>2$ sigma(I)] & $\mathrm{R} 1=0.0491, \mathrm{wR} 2=0.1078$ \\
\hline R indices (all data) & $\mathrm{R} 1=0.0824, \mathrm{wR} 2=0.1237$ \\
\hline Largest diffence peak and hole & 0.647 and $-0.439 \mathrm{e} . \AA^{-3}$ \\
\hline
\end{tabular}

Diffraction data were collected at $100 \mathrm{~K}$ on a Bruker AXS diffractometer using a SMART 6000 $\mathrm{CCD}$ detector on a three-circle platform goniometer with $\mathrm{Cu}(\mathrm{K} \alpha)$ radiation $(\lambda=1.54178 \AA)$ from a microfocus rotating anode generator equipped with Incoatec multilayer optics. Eight $\omega$-scans at different $\phi$-positions were performed to ensure appropriate data redundancy (5.8). A semiempirical absorption correction (SADABS) was applied based on the intensities of symmetryrelated reflections. 
The crystal structure was solved by dual space-recycling methods and refined based on full-matrix least-squares on F2 using the SHELXTL program suite (Sheldrick GM (2001)). Anisotropic displacement parameters were used for all non-hydrogen atoms, unless stated otherwise. Hydrogen atoms were calculated in idealized positions and refined using a riding model.

Dianion 14 crystallizes as a mono-THF solvate (O81-C85). The solvent molecule is disordered over three positions $\mathrm{a}, \mathrm{b}, \mathrm{c}$ with occupancies $\mathrm{a}=0.51, \mathrm{~b}=0.27, \mathrm{c}=0.22$. Orientation $\mathrm{b}$ and $\mathrm{c}$ were refined isotropically. Each of the four magnesium ions is coordinated by two other THF molecules, three of the eight THF molecules are disordered over two orientations $\mathrm{a}, \mathrm{b}$ with occupancies $\mathrm{a}=0.60, \mathrm{~b}=0.40$ for O46-C50, $\mathrm{a}=0.58, \mathrm{~b}=0.42$ for O66-C70, and $\mathrm{a}=0.54, \mathrm{~b}=0.46$ for O71C75. In the disordered parts similarity restraints were used on displacement parameters and distances.

A thermal ellipsoid plot for the crystal structure of dianion 14 is shown in Figure S1. Anisotropic displacement ellipsoids show $50 \%$ probability levels, hydrogen atoms are drawn as circles with small radii. The crystal was grown from an oversaturated solution of THF. 


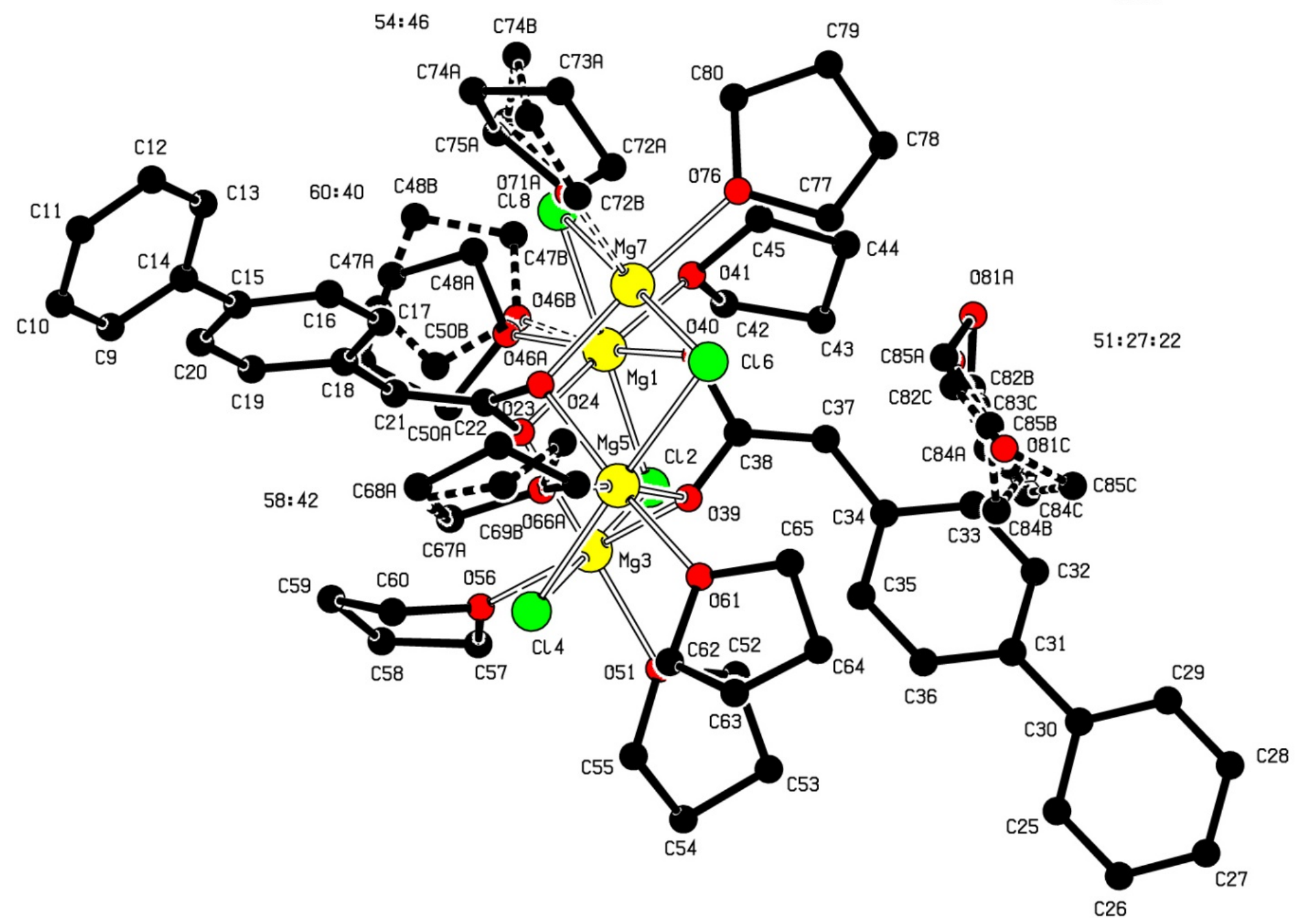

Figure S1: Structure of dianion 14 in the crystal along with the numbering scheme used. Dotted lines mark minor occupancy orientations. All atomic radii are arbitrary, solvent molecules and disorder are omitted for clarity. 


\section{NMR spectra}

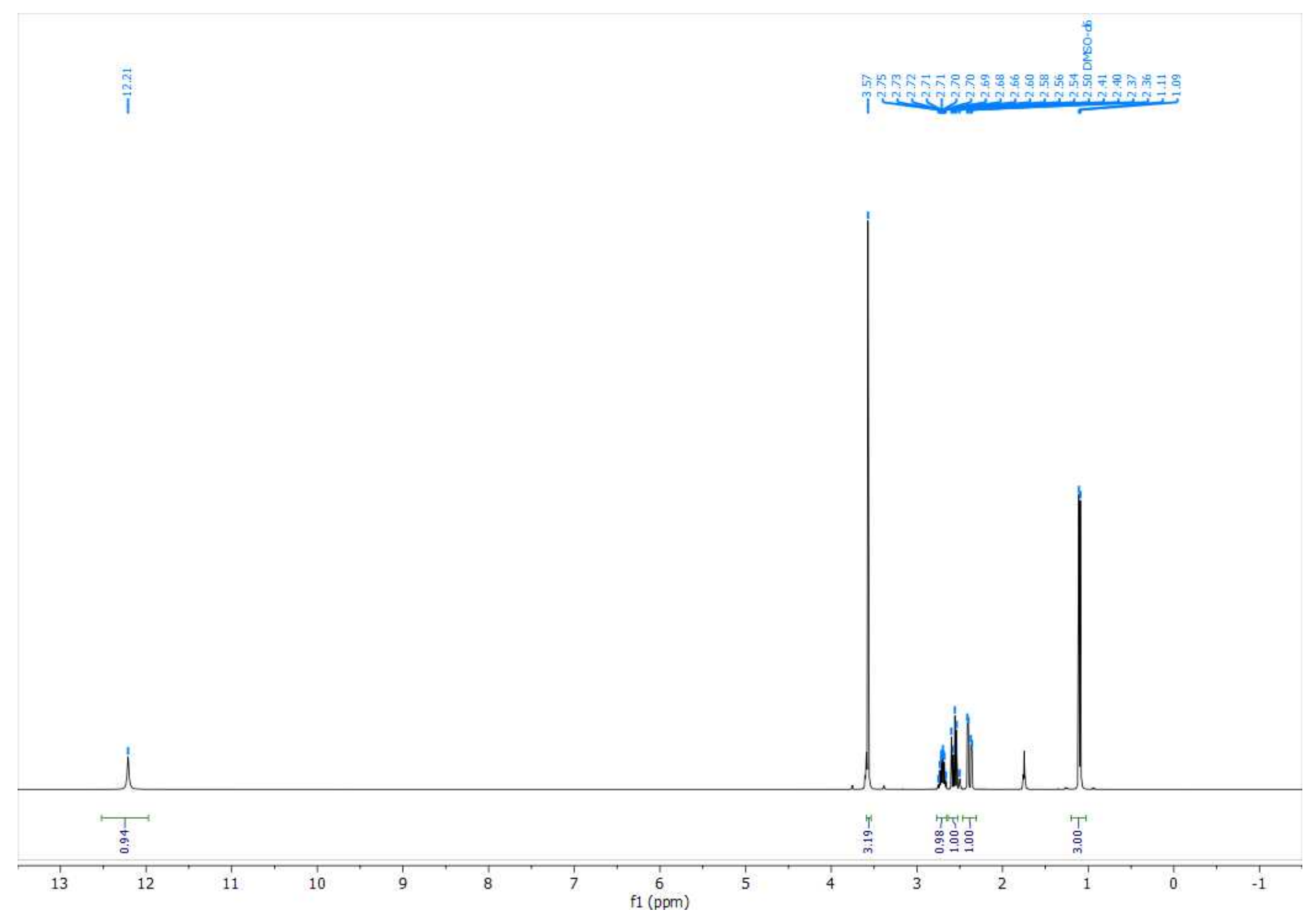

Figure S2: $400 \mathrm{MHz}{ }^{1} \mathrm{H}-\mathrm{NMR}$ spectrum of compound 9 (recorded in DMSO-d ${ }_{6}$ ) 


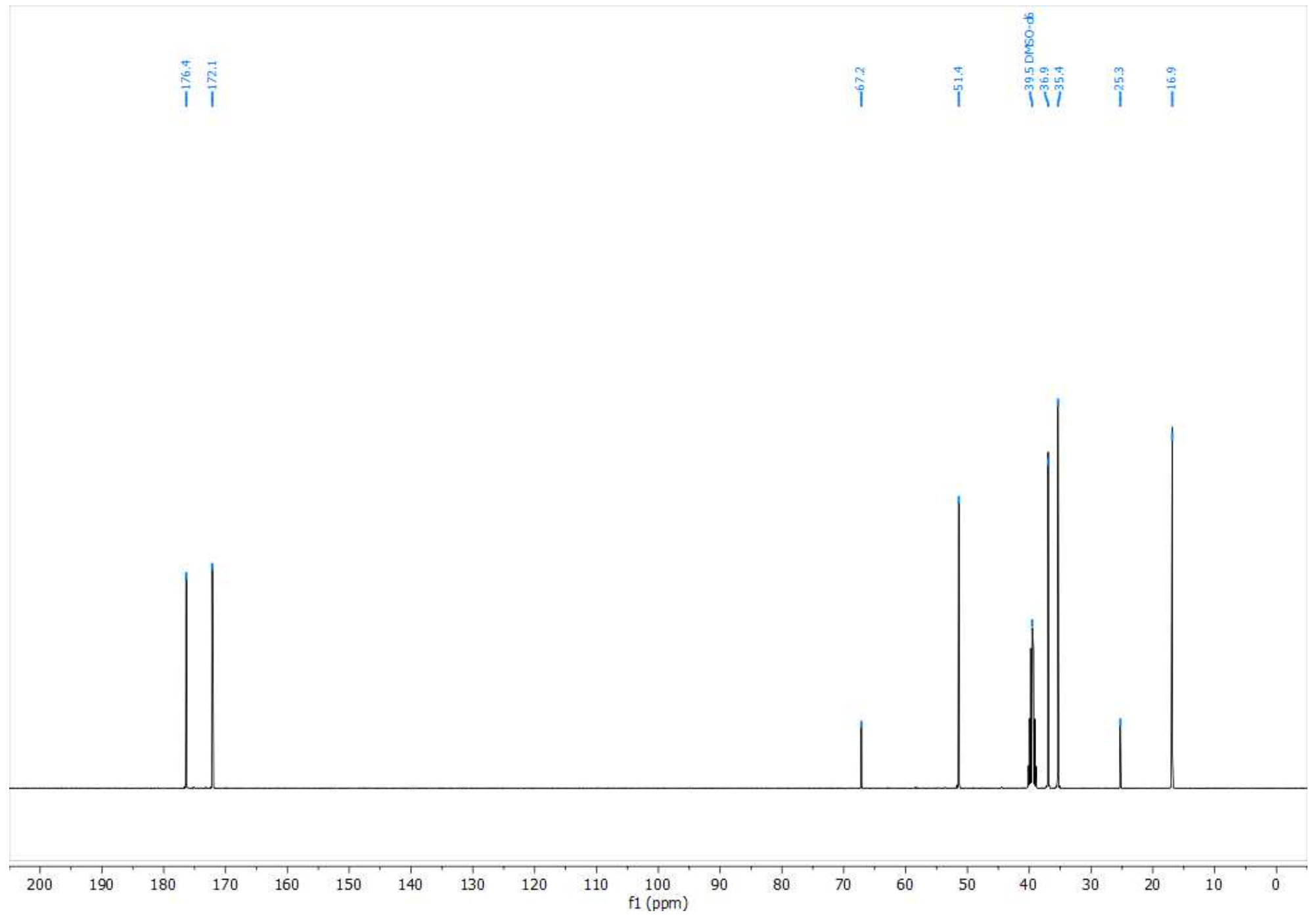

Figure S3: $100 \mathrm{MHz}{ }^{13} \mathrm{C}\left\{{ }^{1} \mathrm{H}\right\}-N M R$ spectrum of compound 9 (recorded in DMSO- $d_{6}$ )

ST 


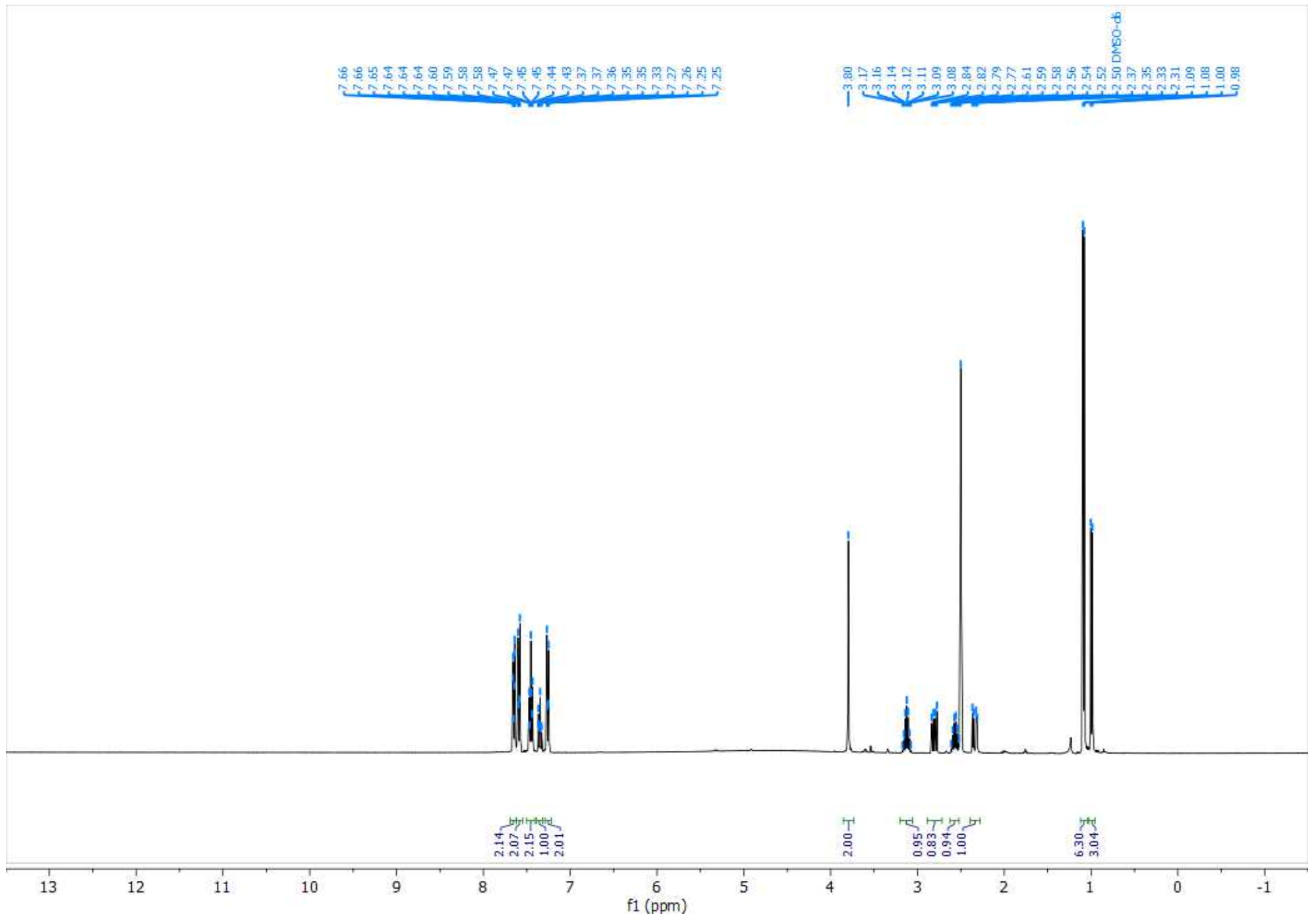

Figure S4: $400 \mathrm{MHz}{ }^{1} \mathrm{H}-\mathrm{NMR}$ spectrum of compound 11 (recorded in DMSO-d $\mathrm{d}_{6}$ )

So 


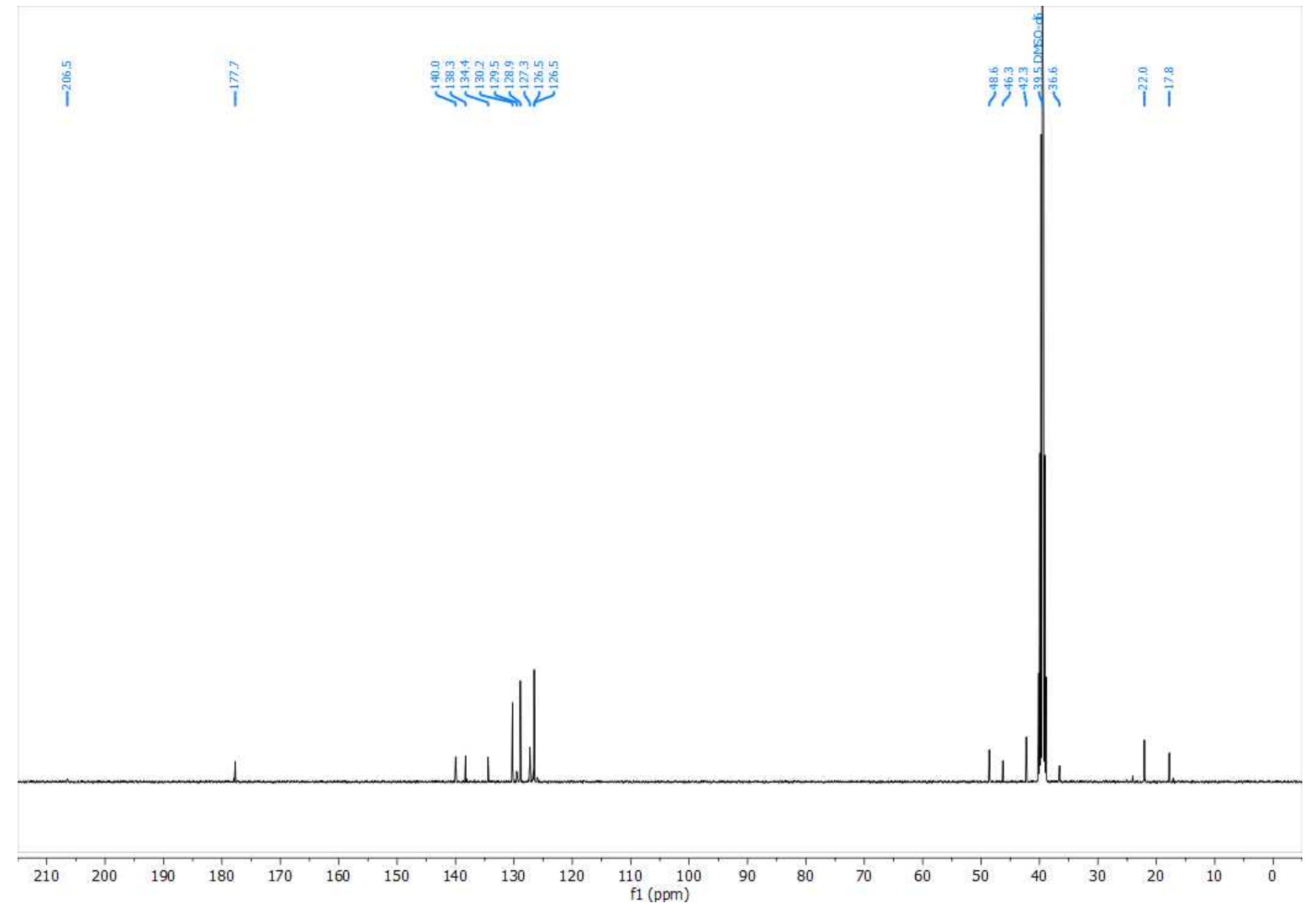

Figure S5: $100 \mathrm{MHz}{ }^{13} \mathrm{C}\left\{{ }^{1} \mathrm{H}\right\}-N M R$ spectrum of compound 11 (recorded in DMSO- $d_{6}$ ) 


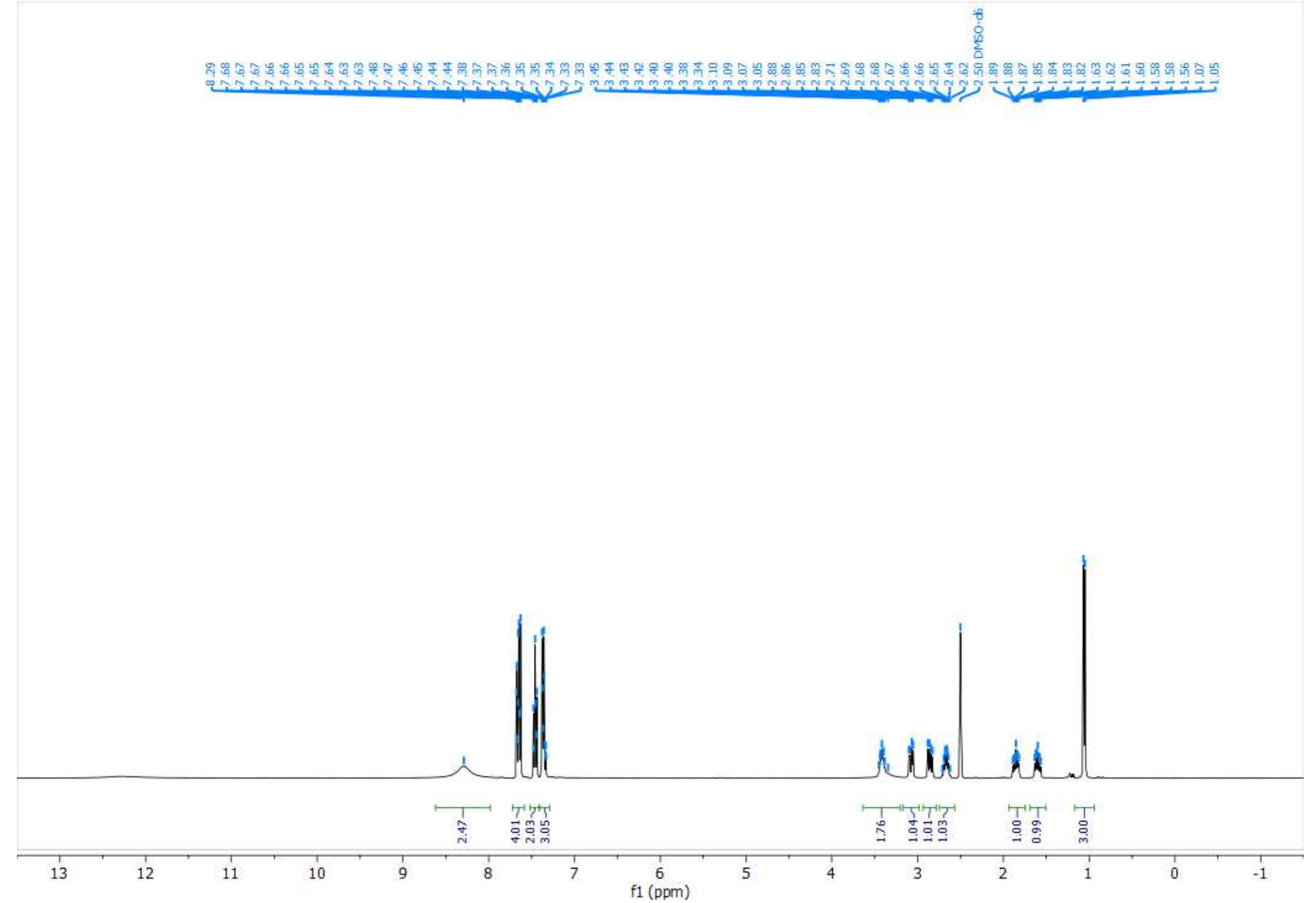

Figure S6: $400 \mathrm{MHz}{ }^{1} \mathrm{H}-\mathrm{NMR}$ spectrum of compound 12 (recorded in DMSO-d $\mathrm{d}_{6}$ ) 


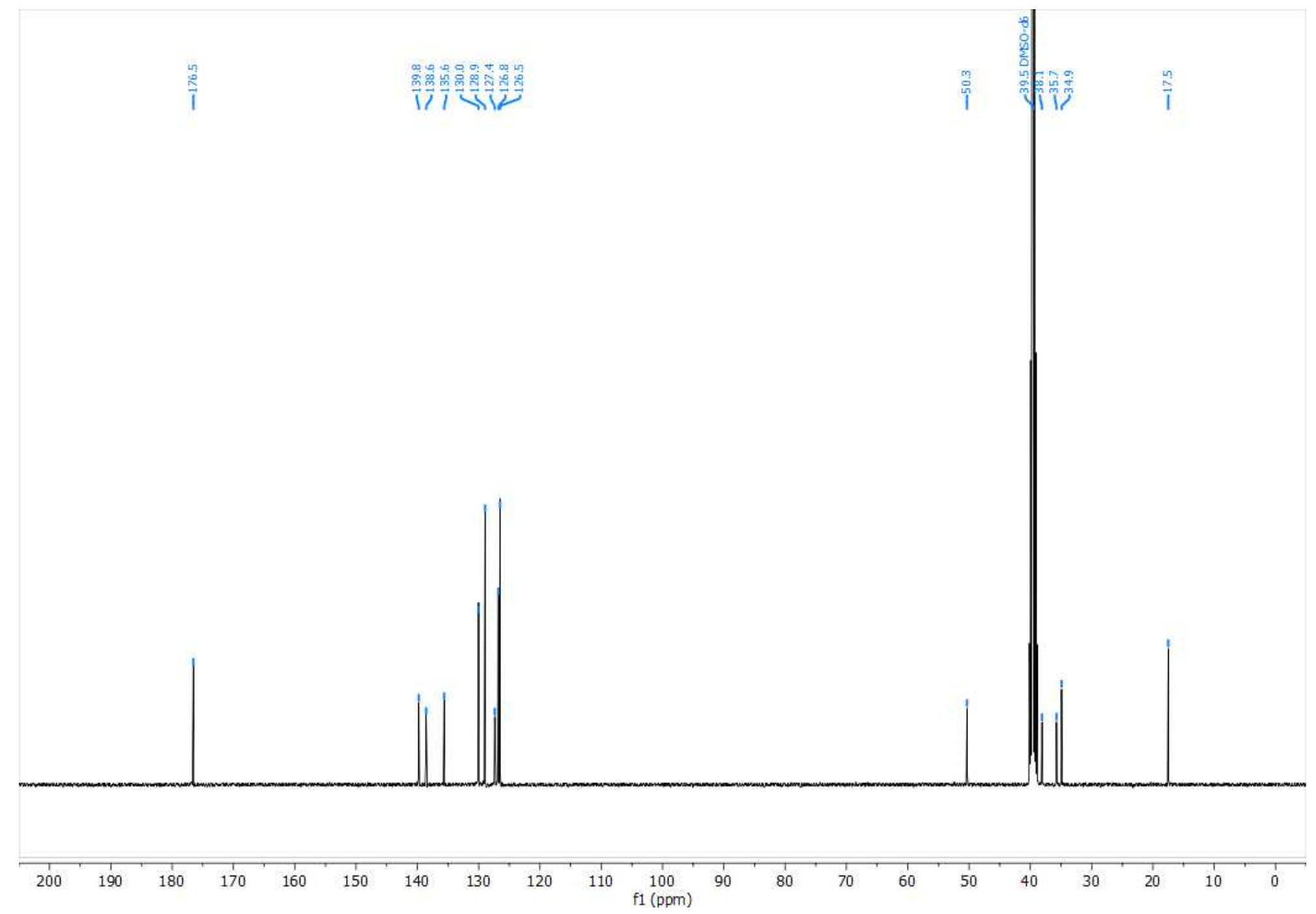

Figure S7: $100 \mathrm{MHz}{ }^{13} \mathrm{C}\left\{{ }^{1} \mathrm{H}\right\}-N M R$ spectrum of compound 12 (recorded in DMSO- $d_{6}$ ) 


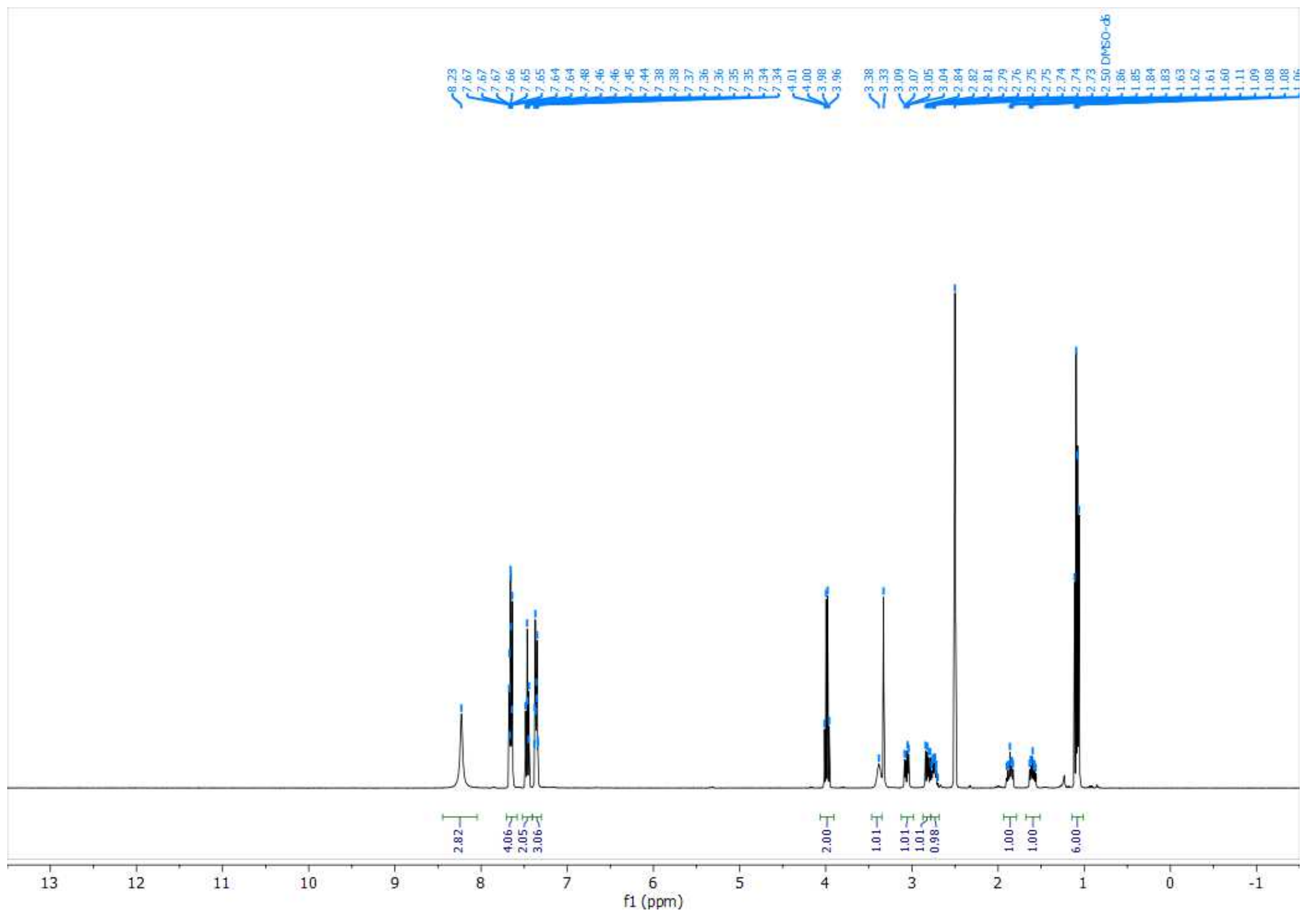

Figure S8: $400 \mathrm{MHz}{ }^{1} \mathrm{H}-\mathrm{NMR}$ spectrum of compound 6 (recorded in DMSO-d $\mathrm{d}_{6}$ )

$\mathrm{S} 12$ 


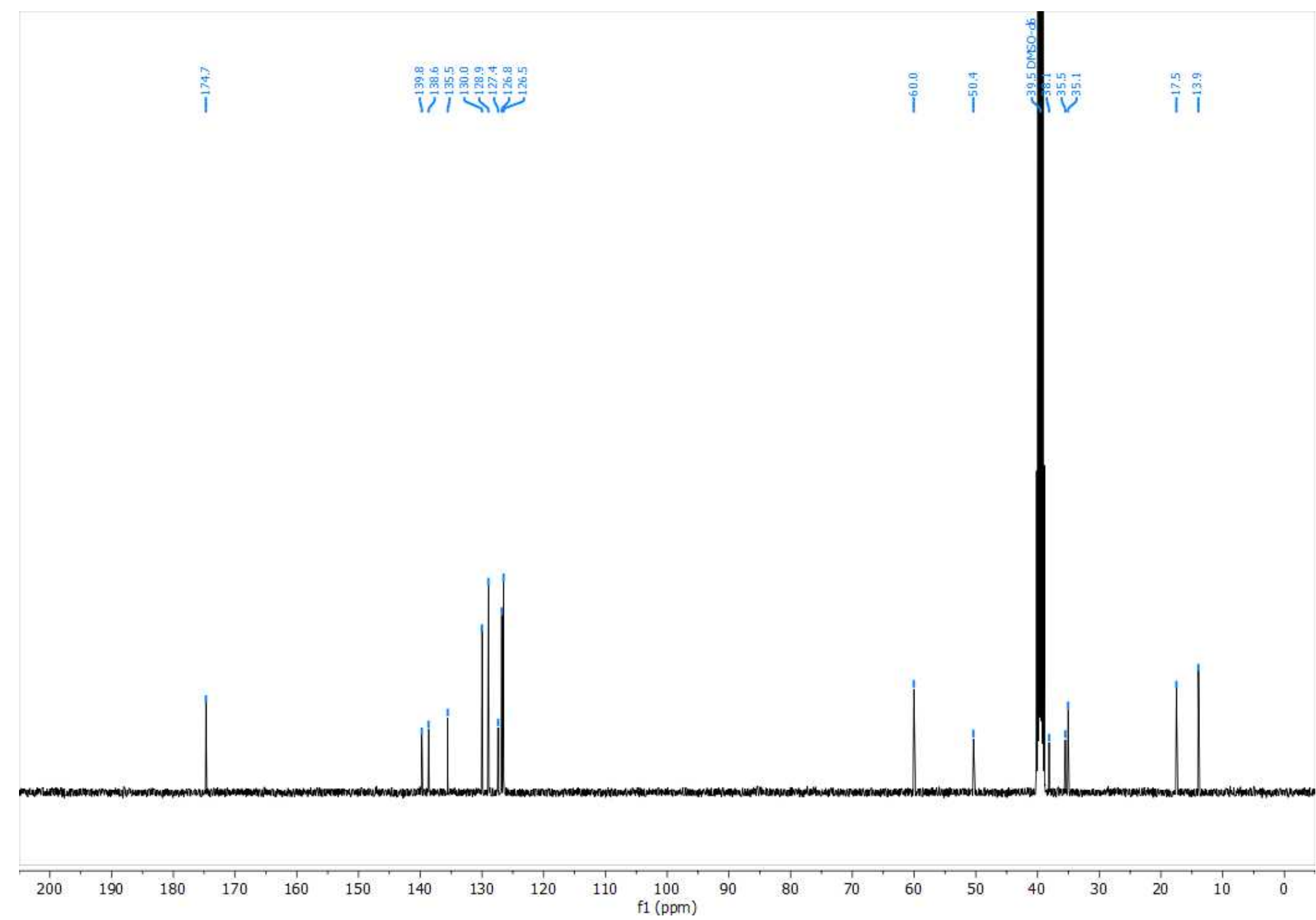

Figure S9: $100 \mathrm{MHz}{ }^{13} \mathrm{C}\left\{{ }^{1} \mathrm{H}\right\}-N M R$ spectrum of compound 6 (recorded in DMSO-d $d_{6}$ ) 


\section{HPLC data}

Column: Daicel Chiralpak AY-3; length $150 \mathrm{~mm}$, internal diameter $4.6 \mathrm{~mm}$, particle size $3 \mu \mathrm{m}$

Detector: ultraviolet (UV), $210 \mathrm{~nm}$

Chromatographic conditions: isocratic, $0.1 \%$ acetic acid in heptane:isopropanol 90:10; flow rate $1.0 \mathrm{~mL} / \mathrm{min}$; column temperature $30^{\circ} \mathrm{C}$

Sample preparation: derivatization with diisopropyl azodicarboxylate (DIAD), triphenylphosphine and benzyl alcohol in THF

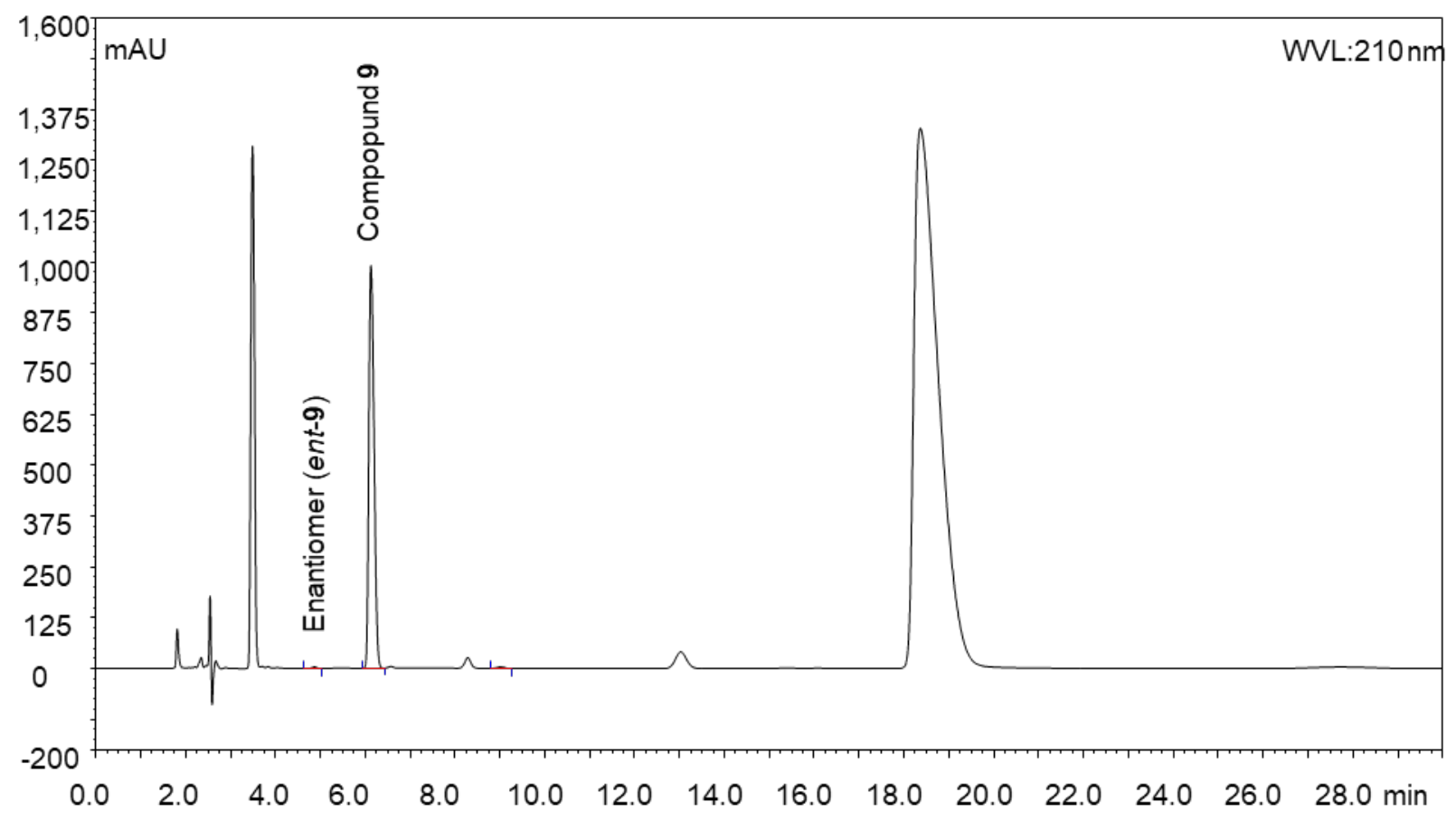

Figure S10: HPLC chromatogram for determination of the enantiomeric purity compound 9 


\section{RC1 data}

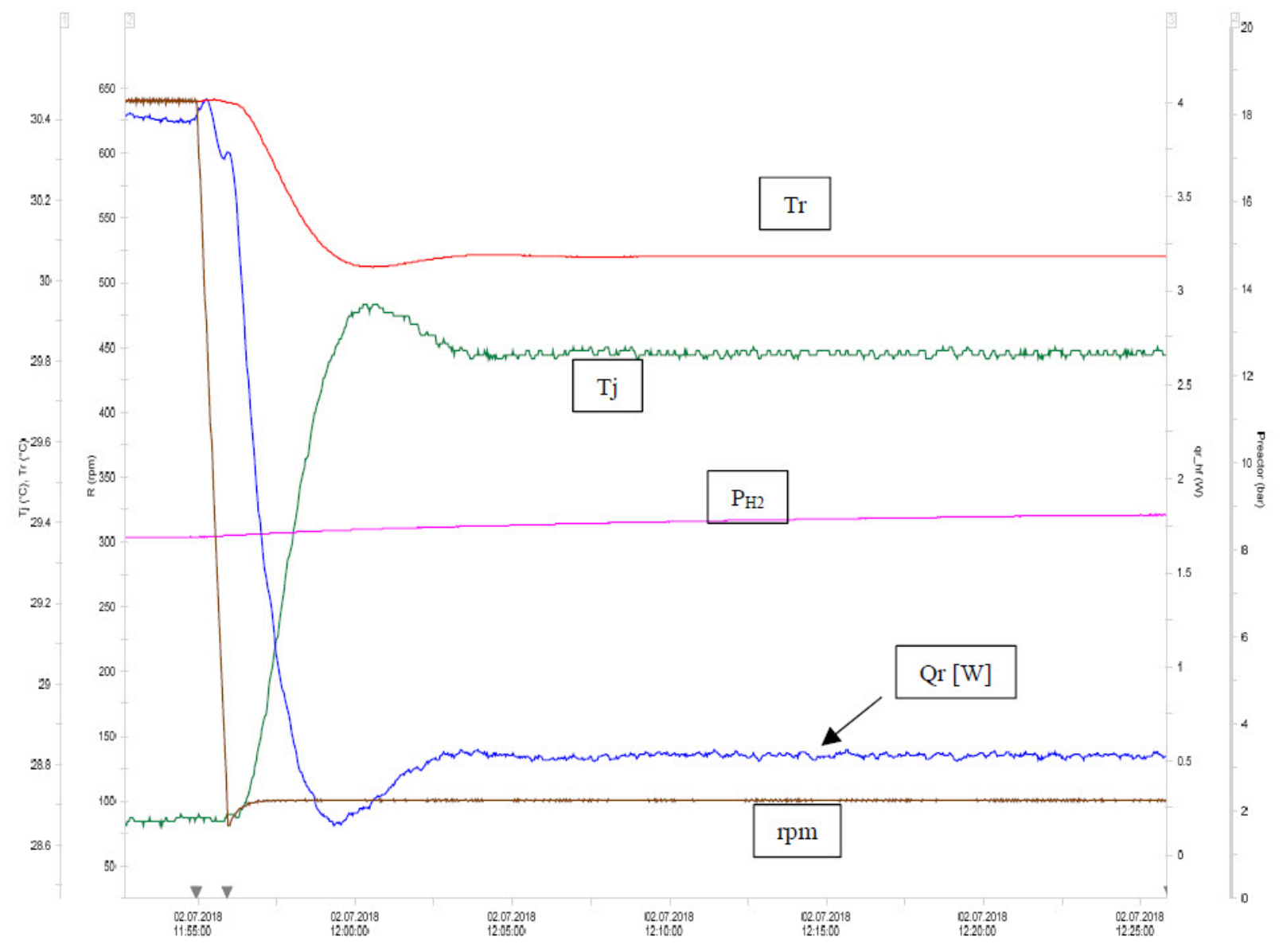

Figure S11: RC1 graphs for hydrogenation of compound 8-impact of stirring speed

Note: $\mathrm{Tr}=$ temperature of reaction mass (in ${ }^{\circ} \mathrm{C}$ ); $\mathrm{Tj}=$ temperature of reactor jacket (in ${ }^{\circ} \mathrm{C}$ ); $\mathrm{PH} 2=$ hydrogen pressure (in bar); $\mathrm{Qr}=$ heat flow (in W); rpm = stirring speed (in rounds per minute) 


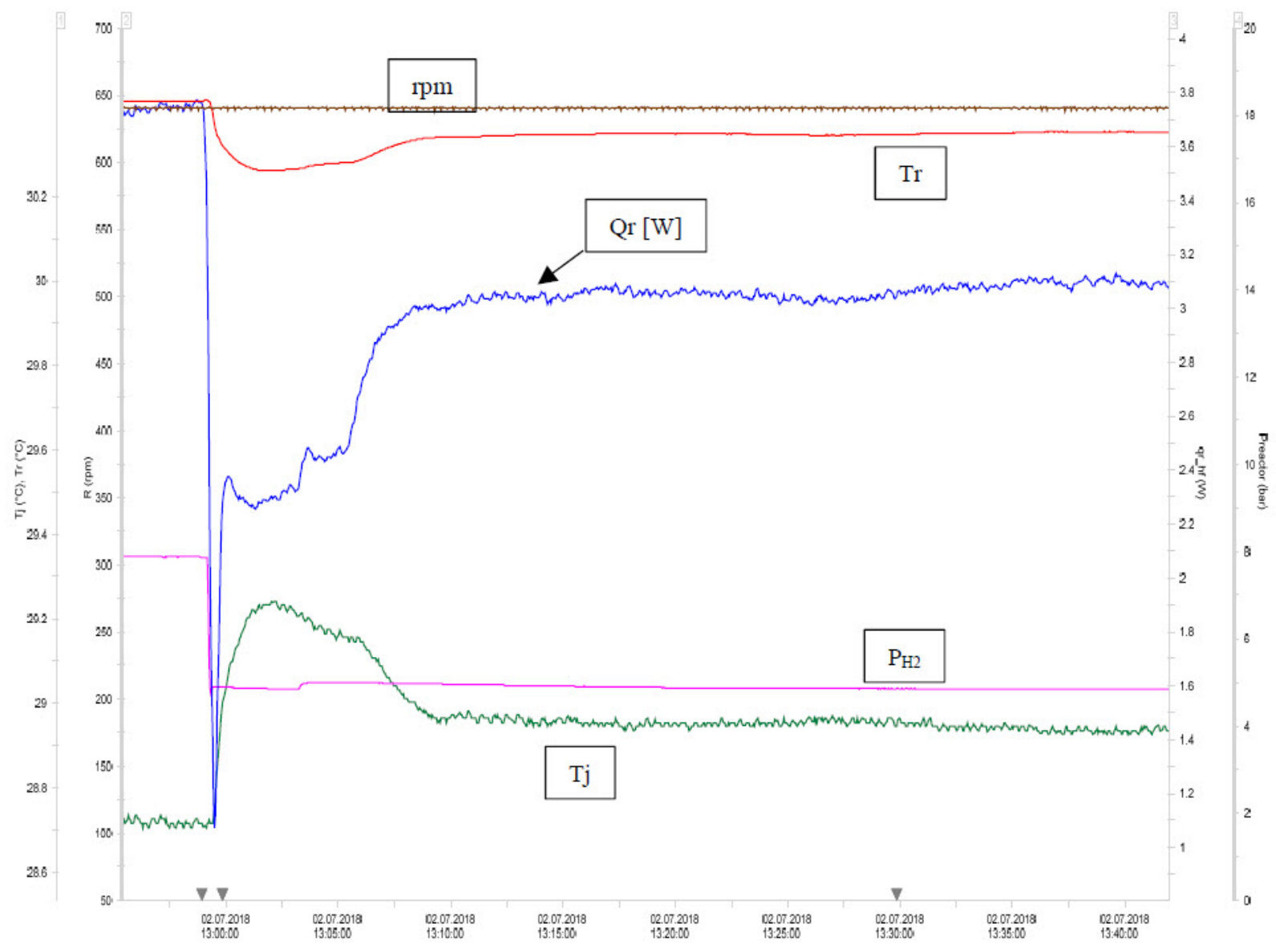

Figure S12: RC1 graphs for hydrogenation of compound 8-impact of pressure

Note: $\mathrm{Tr}=$ temperature of reaction mass (in ${ }^{\circ} \mathrm{C}$ ); $\mathrm{Tj}=$ temperature of reactor jacket (in ${ }^{\circ} \mathrm{C}$ ); $\mathrm{PH} 2$ = hydrogen pressure (in bar); $\mathrm{Qr}=$ heat flow (in $\mathrm{W}$ ); rpm = stirring speed (in rounds per minute) 


\section{Equipment for flow reaction}

\section{Pumps}

Hermetic inert pump series mzr- $7255^{1}$

Flow meters

Coriolis Mass Flow Meter Bronkhorst M14-AAD-11-0- $\mathrm{H}^{2}$

Pre-coolings

PFA $1 / 4$ inch tube

In-line filters

Filter F-MI3 ${ }^{3}$

Reactor 1

PTFE tube: $5 \mathrm{~mm}$ ID, $8 \mathrm{~mm}$ OD; with static mixers ${ }^{4}$

\section{Reactor 2}

PTFE tube: $5 \mathrm{~mm}$ ID, $8 \mathrm{~mm}$ OD; with static mixers ${ }^{4}$ plus PFA $1 / 4$ inch tube

\section{Fittings, back-pressure regulator and T-pieces}

Swagelok 5

1 HNP Mikrosysteme, Hermetic inert pump series mzr-7255. https://www.hnpmikrosysteme.de/en/products/micro-annular-gear-pumps/hermetic-inert-pump-series/mzr-7255 (accessed May 06, 2020)

2 Datasheet M14, Coriolis Mass Flow Meter for Liquids and Gases. https://www.massflow.ru/u/www/files/catalog/m14-mini-cori-flow.pdf (accessed May 06, 2020)

3 HNP Mikrosysteme, Filter series F-MI3. https://www.hnp-mikrosysteme.de/en/products/detail/filter-series-fmi3/ (accessed May 06, 2020)

4 ESSKA.de, Statisches Mischelement - PA12-Glasfaser-verstärkt 70\%/30\%. https://www.esska.de/shop/Statisches-Mischelement-PA12-Glasfaser-verstaerkt-70\%25-30\%25--30420000000011800 ?hlid $=304200812095$ \&emcs $0=3 \&$ emcs $1=$ Kategorieseite $\% 20-\% 20$ Topseller\&emcs $2=\&$ emcs $3=304200000$ 000 (accessed May 06, 2020)

5 Swagelok Home Page. https://www.swagelok.com/en (accessed May 06, 2020) 